\title{
PRIMARY DNA DAMAGE IN BRAIN OF MICE EXPOSED TO ANAESTHETIC ISOFLURANE AND IONIZING IRRADIATION IN DOSE OF 1 OR 2 Gy
}

\author{
Vesna Benkovićí, Anica Horvat Knežević', Mirta Milićn
}

\author{
${ }^{1}$ Department of Biology, Faculty of Science, University of Zagreb, Zagreb, Croatia \\ ${ }^{2}$ Mutagenesis Unit, Institute for Medical Research and Occupational Health, Zagreb, Croatia
}

\begin{abstract}
Radiotherapy (RT) is still a golden procedure for brain tumour therapy. Ionizing radiation (IR) is IARC carcinogen of group 1 and the use of novel RT techniques increased the precise targeting, dose delivery, localized dose exposure and lowered the number of necessary IR exposures. The use of volatile anaesthetics (VA) in RT helped in patients' immobility and RT targeting either due to the type of the procedure or due to different patients' conditions (claustrophobia, anxiety, etc.), considering the increase in brain tumour incidence among adults and children. Isoflurane (ISO) among VA is commonly used due to fast sedation and stable patients' conditions. Although considered safe, there are reports about its genotoxicity and mutagenicity in vitro, in vivo and in clinical studies but with no consistent and even contradictory results, mostly considering the toxic and protective effects in brain cells. Combined $V A-I R$ effects have not been examined so far, so we decided to test single exposure on brain cells in vivo. 120 Swiss albino male mice, were exposed to $2.4 \%$ ISO $\mathbb{R}$ for 2 hours or to 1 or $2 \mathrm{~Gy}$ whole body $\gamma$-IR $\left({ }^{6 \circ} \mathrm{Co}\right.$, dose rate $\left.1.88 \mathrm{~Gy} / \mathrm{min}\right)$ or their combination. Frontal lobe brain samples (as the most sensitive IR damaging parts) were taken immediately (oh), 2, 6 and $24 \mathrm{~h}$ from the exposure and primary DNA damage was evaluated using alkaline comet assay. In non-irradiated ISO samples slightly higher damage level did not significantly differ from control in all time points. IR only samples had significantly higher damage, with the dose increase. In both combined exposures, after 24 hours, ISO significantly decreased damage levels, compared to IR samples and demonstrated its influence on increased velocity repair of the rest of IR damage. Adaptive response, by activating DNA repair mechanisms and the levels of reactive free oxygen radicals' scavengers are possible mechanism of isoflurane protective effect but further research should be focused on determining the exact mechanisms.
\end{abstract}

Keywords: Alkaline comet assay, cellular repair index, DNA damage, DNA repair, gamma radiation, radiotherapy, tail intensity, volatile anaesthetics

\section{INTRODUCTION}

In the last decades there are increasing evidence about damaging effects after VA (volatile anaesthetics) exposure in occupational personnel, patients, in vivo (3 consecutive days) and in vitro studies, and with increasing yearly number of combined radiotherapy and VA exposure, there is increased concern about possible synergistic effect and patients (and workers) safety, considering that ionizing radiation (IR) used in radiotherapy is already known cytotoxic and genotoxic agent and the exposure should, therefore, be kept at minimum [1]-[5].

By direct ionization and through generation of toxic free radicals, IR radiation accompanied with damage to critical biomolecules like lipids, proteins, and DNA through radiolysis of cellular water, causes single strand breaks, double strand breaks, oxidative damage to sugar and base residues, chromosomal aberration and mutation, without distinguishing between tumour and normal tissues [4], [6]. Usual IR doses in diverse types of radiotherapy procedures (intraoperative radiotherapy, brachytherapy, fractionated and hypofractionated radiotherapy) are 2 or $1 \mathrm{~Gy}$ [6].

VA are enhancing inhibitory postsynaptic channel activity (gamma-aminobutyric acid (GABA) and glycine) and inhibiting excitatory synaptic channel activity (N-methyl-D-aspartate (NMDA), nicotinic acetylcholine, serotonin, and glutamate) in the central nervous system [7].

Nowadays, radiotherapy is focused on precision to target only target tissue, but healthy nearby tissue can be also damaged, and VA can be of great help in precise targeting and lowering the number of necessary received curation doses, fast sedation and stable conditions in patients during the procedure [6], [8].

One of the ways to estimate the exposure effect on cells is the assessment of cells DNA damage and repair either in vivo or in vitro conditions. Single cell gel electrophoresis assay (alkaline comet assay) is a simple, cheap and sensitive worldwide used technique for genotoxic in vivo (OECD 2014, TG 489) and human biomonitoring studies of exposure to anaesthetics and IR [9]-[13]. Dynamics of DNA damage and repair depends on gender (females more prone), on target tissue organ and time from the exposure, and is usually monitored immediately after, 2, 6 and 24 hours from the exposure [2], [11], [14]. Considering the target organ, brain consumes nearly $20 \%$ of the oxygen in the body with high metabolic rate and is highly susceptible organ to radiation-induced oxidative stress [15], [16]. The effect of VA is seen also from its metabolized

\footnotetext{
*vesna@biol.pmf.hr
} 
products in liver that are circulating in the blood before the excretion, and with high fluctuation of blood also in brain, this makes the brain also again VA sensitive.

\section{MATERIALS AND METHODS}

\subsection{Ethical approval}

The study has been approved by the Ethics Committee of the Faculty of Science (University of Zagreb, Croatia; No. 251-58-508-11-9) and designed in accordance with relevant Croatian guidelines: Animal Protection Act [17] (OG, 102/17), the Ordinance on the protection of animals used for scientific purposes [18] (OG, 55/13; 39/17) and EU Directive 2010/63/EU [19].

\subsection{Chemicals}

If not specified otherwise, chemicals and reagents were purchased from Sigma-Aldrich Chemical Co. (St. Louis, MO, USA). Inhalation anaesthetics isoflurane (Forane $®$ ) was provided by Abbott Laboratories LTD (Queenborough, UK).

\subsection{Animals, anaesthesia and irradiation}

In the breeding unit of the Department of Biology, Faculty of Science, University of Zagreb, Croatia, Swiss albino male mice were housed in standard breeding conditions $\left(22 \pm 1^{\circ} \mathrm{C}\right.$, humidity $50-70 \%, 12 / 12$ hours' light/dark cycle photoperiod, fed with standard laboratory diet (Standard Diet GLP, 4RF 1, Mucedola, Settimo Milanese MI, Italy), with water ad libitum). When mice body weight reached 20-25 grams $(60 \pm 5$ days old), they were randomly divided into 17 groups (each comprising 5 animals), anesthetized with isoflurane and exposed to $1 \mathrm{~Gy}$ or $2 \mathrm{~Gy}$ of IR. Doses of IR are selected based on our previously studies and newest version of the Guidelines of the Royal College of Radiologists [5], [6]. Appropriated control groups were established (Fig. 1).

\subsection{Sacrifice, sampling, alkaline comet assay}

Except for the control and only IR groups, mice were anesthetized in an induction chamber connected to an anaesthetic machine (Sulla 800; Dräger) with a compatible evaporator in which $1.7 \mathrm{vol} \%$ isoflurane was mixed with a 50:50 mixture of oxygen and air (3 L / min) in continuous flow for $2 \mathrm{~h}$. Acceptable deep anaesthesia was achieved when mice were sleeping calmly, breathing spontaneously, and not wiggling their tail. This stage of anaesthesia corresponds to classified stage 3 - Surgical Anaesthesia according to "Stages of Anaesthesia Based on Guedel's Classification" and recommended VA doses used in this study provide appropriate and gentle restraint, a sufficient amount of analgesia to diminish pain sensation during the procedure, and relaxation of muscle tone [20], [21].

The mice determined for combined treatment after 2 hours of anaesthesia, were irradiated with 1 Gy or 2 Gy $\gamma$-radiation at a dose rate of $1.88 \mathrm{~Gy} / \mathrm{min}$ (6oCo source, Theratron Phoenix teletherapy unit, Atomic Energy Ltd., at the Clinical Hospital "Sveti Duh") as well as the groups for radiation only.

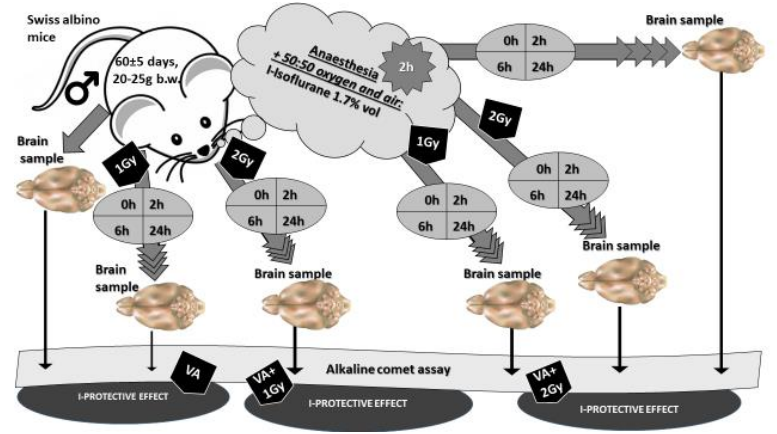

Figure 1. Sheme and the results of the experiment

Animals were sacrificed by cervical dislocation according to laboratory animal legislation (OG, 55/13; 39/17). Small pieces of freshly resected mice brain tissue from frontal lobe were mechanically homogenized using chilled homogenization buffer (0.075 $\mathrm{M} \mathrm{NaCl}$ and $0.024 \mathrm{M} \mathrm{Na}_{2}$ EDTA, kept at $4{ }^{\circ} \mathrm{C}$, freshly prepared, the ratio was $1 \mathrm{~g}$ of tissue for $1 \mathrm{ml}$ of buffer). Single cell suspension was done by mincing and passing the homogenized sample through a stainless-steel mash. For each animal and sample there was $10 \mu \mathrm{l}$ of single cell suspension homogenate at $4^{\circ} \mathrm{C}$ that was immersed into agarose gels immediately after sample preparation.

The alkaline comet assay or single cell gel electrophoresis assay was carried out under alkaline conditions in standardized conditions, as already described in previous work on blood and brain samples of similarly exposed Swiss albino mice to VA and cisplatin for 3 consecutive days with few modifications (10). On already earlier that day precoated microscopic slides (Biognost, Zagreb, Croatia) (300 $\mu \mathrm{l}$ of $1 \%$ normal melting point (NMP) agarose and then with the $300 \mu \mathrm{l}$ layer of $0.6 \%$ low melting point (LMP) agarose), $10 \mu \mathrm{l}$ of single brain cell suspension was mixed with $100 \mu$ of $0.5 \%$ LMP agarose (freshly prepared, kept at $37^{\circ} \mathrm{C}$ in water bath) and layered above and covered with coverslips (Biognost, Zagreb, Croatia). Slides were kept horizontally at $4{ }^{\circ} \mathrm{C}$ for 10 minutes and afterwards another layer of $0.5 \%$ LMP agarose was placed on top. After solidification and coverslip removal, slides were immersed for two hours at $4^{\circ} \mathrm{C}$ in a freshly prepared ice-cold lysis solution (2.5 M NaCl, $100 \mathrm{mM}$ Na2EDTA, $10 \mathrm{mM}$ Tris- $\mathrm{HCl}, 1 \%$ sodium sarcosinate, $\mathrm{pH} 10$, with $1 \%$ Triton X-100 and $10 \%$ dimethyl sulfoxide (Kemika, Zagreb, Croatia)). Denaturation and electrophoresis were carried out at $4{ }^{\circ} \mathrm{C}$ under dimmed light in a freshly prepared denaturation solution (300 $\mathrm{mM} \mathrm{NaOH}, 1 \mathrm{mM}$ Na2EDTA, pH 13). After 20 min of denaturation, slides were randomly placed in a horizontal gelelectrophoresis unit, facing the anode, and electrophoresis was carried out in the same by ingredients but new freshly prepared cold alkaline (denaturation) solution for $20 \mathrm{~min}$ at $25 \mathrm{~V}(300 \mathrm{~mA}$, $0.8 \mathrm{~V} / \mathrm{cm}$ ). After electrophoresis, slides were neutralized three times at five-minute intervals by adding $0.4 \mathrm{M}$ Tris-HCl buffer, $\mathrm{pH}$ 7.5. All samples were done in duplicate. Images of 40 randomly selected cells were analysed for each sample (animal). After staining with ethidium bromide $(20 \mu \mathrm{g} / \mathrm{mL}, 10$ minutes $)$, slides were examined using an epifluorescence microscope (Olympus BX40, Tokio, Japan, 200x magnification) with a CCD camera with a computer-based image analysis system (Comet Assay IV software, Instem, London, UK). 
A total of 200 comets for each group was analysed. Comets were randomly captured at a constant depth of the gel, avoiding the edges of the gel, occasional death cells, and superimposed comets. DNA damage was determined as the tail length (TL, distance of DNA migration from the center of the body of the nuclear core, expressed in $\mu \mathrm{m}$ ) tail intensity (TI, percentage of genomic DNA that migrated during the electrophoresis from the nuclear core to the tail). These parameters are usually represented together in most of our work on DNA damage assessment after IR or anaesthetics exposure to compare whether all of the parameters followed the same pattern, although the most important one is the TI that demonstrates the actual amount of damaged DNA in the comet tail.

\subsection{Cellular DNA repair index}

Cellular DNA repair index (CRI) was calculated from the medians of TI parameter according to the formula by Nair \& Nair [22]. Defined as the percentage decrease from the initial value of the parameter due to repair, CRI serves to quantify the cells efficiency to repair and rejoin strand breaks in DNA following different treatments, and can also show whether the treatment had the influence on faster, slower or delayed repair than in control samples:

$$
C R I=\left[1-\left(\frac{\text { Comet parameter at time } t}{\text { Comet parameter at initial time t } 0}\right)\right] \times 100
$$

\subsection{Statistical analysis}

Statistical analysis was performed by Statistica 9.0 (Statsoft, Tulsa, USA) and Statistica 13.5.0.17 (TIBCO Software Inc., California, Palo Alto, USA). Descriptive statistics of TL, TI and TM parameters were calculated for mean, median, standard deviation (SD) and range of values. Groups were compared by the use of MannWhitney U-test. The level of statistical significance was set at $\mathrm{p} \leq 0.05$.

\section{RESULTS AND DISCUSSION}

Exposure to only isoflurane caused lower TI values in time points oh, $2 \mathrm{~h}$, and $6 \mathrm{~h}$ compared to control.

A significant increase in DNA damage was seen after 1 and 2 Gy irradiation when compared to the control, with more apoptotic cells created after 2 Gy IR dose.

non-irradiated

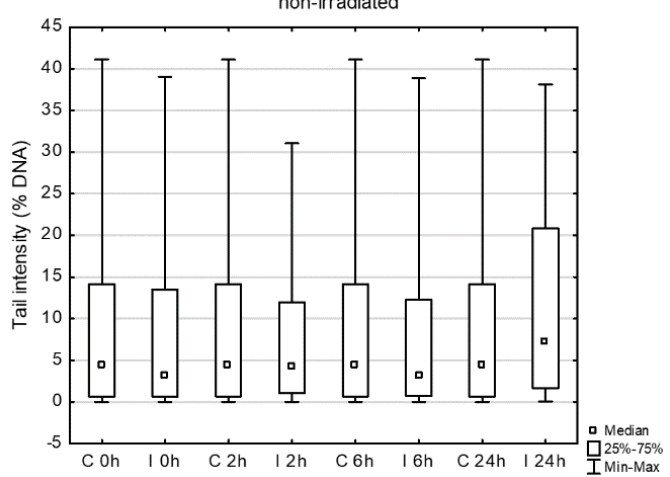

Figure 2. Tail intensity values in brain of Swiss albino mice treated with anesthetic isoflurane (I). Samples were taken immediately, 2, 6 and 24 hours (oh, 2h, 6h, 24h) after exposure to anesthetic. C-control, *statistically different $(\mathrm{p}<0.05)$ from control
In combined isoflurane and $1 \mathrm{~Gy}$ exposure, TI values were lower even significantly in oh and $2 \mathrm{~h}$ compared to control.

Combined isoflurane and 2 Gy exposure showed significantly decreased TI values in all time points except for $6 \mathrm{~h}$ time point when compared to control.

As for CRI, protective effect for both doses was seen for combined isoflurane treatment.

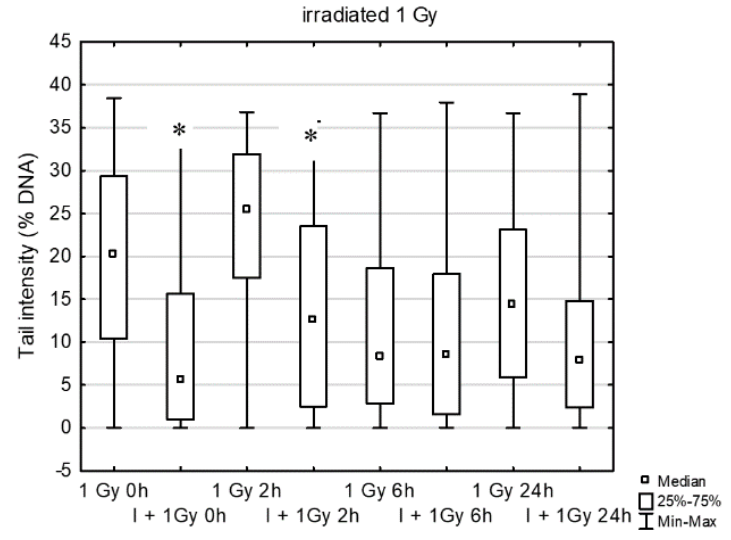

Figure 3. Tail intensity values in brain of Swiss albino mice treated with anesthetic isoflurane (I) in combination with 1 Gy irradiation (IR), Samples were taken immediately, 2, 6 and 24 hours (oh, 2h, 6h, 24h) after IR. C-control, *statistically different $(\mathrm{p}<0.05)$ from control

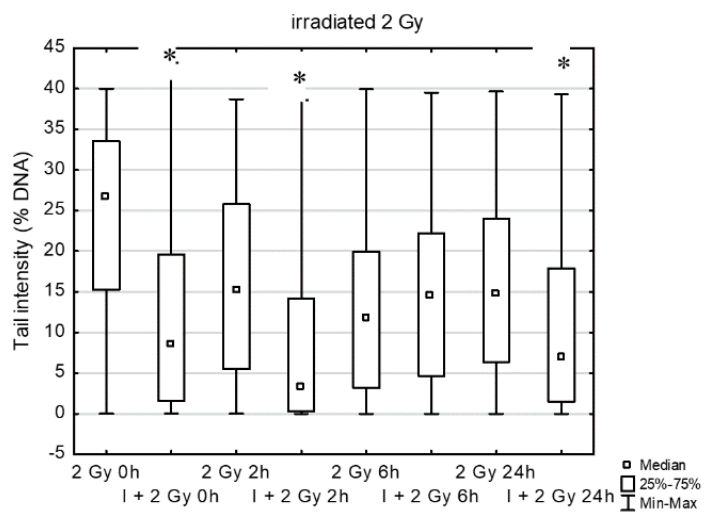

Figure 4. Tail intensity values in brain of Swiss albino mice treated with anesthetic isoflurane (I) in combination with Gy irradiation (IR), Samples were taken immediately, 2, 6 and 24 hours (oh, 2h, 6h, 24h) after IR. C-control, *statistically different $(\mathrm{p}<0.05)$ from $\mathrm{C}$ of the same time point.

Tail intensity

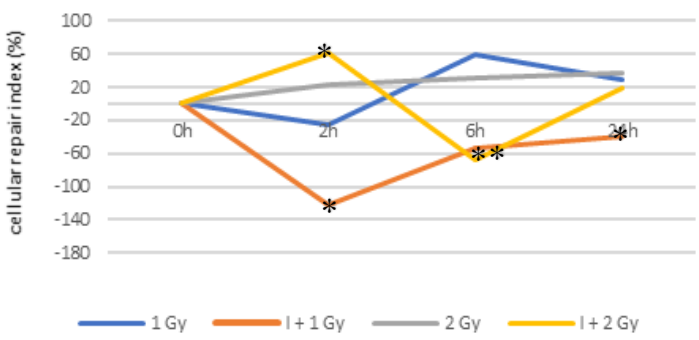

Figure 5. Cellular DNA repair index in brain of Swiss albino mice after the exposure to isoflurane (I) in combination with $1 \mathrm{~Gy}$ or $2 \mathrm{~Gy}$; for samples taken immediately, 2, 6 and 24 hours (oh, 2h, 6h, 24h) after the exposure, ${ }^{*}$-statistically significant difference from the only irradiated samples (1Gy compared to $\mathrm{I}+1 \mathrm{~Gy}$ and $2 \mathrm{~Gy}$ to I+2Gy), p $\leq 0.05$, Mann Whitney U-test 
There are no studies exploring possible synergistic effect of combined single exposure to volatile anaesthetics and 1 or 2 Gy doses used in radiotherapy. Brain samples from Swiss albino male mice exposed to either 1.7 vol \% ISO alone or in combined exposure with 1 or $2 \mathrm{~Gy}$ y-radiation $\left({ }^{\circ} \mathrm{Co}\right)$ dose that were analysed for DNA damage and repair with alkaline comet assay technique demonstrated that isoflurane did not cause any damage in single exposure, and in combined exposure it demonstrated protective effect, both at $1 \mathrm{~Gy}$ and even more at $2 \mathrm{~Gy}$. The results implicate that isoflurane use in radiotherapy has a beneficiary potential to protect irradiated non-tumour tissue and to help in IR protection. ISO preconditioning demonstrated in other studies that after ischemia or hypoxia-oxygenation it elicits mild mitochondrial uncoupling, better protection of cell's functional parameters, attenuated $\mathrm{Ca}^{2+}$ uptake, increases hydrophilic and total antioxidant capacity by modulating heme oxygenase (HO) 1 which exerts antiinflammatory and antioxidative effects. So, although metabolised in body in really small amount, ISO can demonstrate beneficiary effect also in brain cells.

\section{ConClusion}

In both combined exposures, after 24 hours, ISO significantly decreased DNA damage levels, compared to IR samples and demonstrated its influence on increased velocity repair. Even obtained on an in vivo model, findings from this research cannot be directly extrapolated to a human. Protocols used for anaesthesia are quite various, and interpretation and comparisons of conclusions are quite challenging. Future research should be focus on investigation of cellular signal pathways, oxidative stress mechanism, gene expression and mechanisms to understand the mechanisms by which volatile anaesthetics in combined with IR induce DNA damage.

Acknowledgements: The paper was supported by the Institute for Medical Research, Ministry of Science and Education of the Republic of Croatia and University of Zagreb, Faculty of Science, Department of Biology. The authors would like to thank to Prof. Makso Herman for English editing.

\section{REFERENCES}

1. P. Jaloszyński, et al., "Genotoxicity of inhalation anesthetics halothane and isoflurane in human lymphocytes studied in vitro using the comet assay," Mutat. Res., vol. 439, no. 2, pp. 199-206, Feb. 1999. DOI: $10.1016 / \mathrm{s} 1383-5718(98) 00195-8$ PMid: 10023059

2. L. Karabiyik, et al., "Comparison of genotoxicity of sevoflurane and isoflurane in human lymphocytes studied in vivo using the comet assay," Mutat. Res., vol. 492, no. 1-2, pp. 99-107. May 2001.

DOI: 10.1016/s1383-5718(01)00159-0 PMid: 11377249

3. M. G. Braz, et al., "Genotoxicity, cytotoxicity and gene expression in patients undergoing elective surgery under isoflurane anesthesia," Mutagenesis, vol. 26, no. 3 , pp. 415-420. May 2011.

DOI: $10.1093 /$ mutage/geq109

PMid: 21257718

PMCid: PMC3081333
4. Radiation, vol. $100 \mathrm{D}$, IARC Monographs on the Evaluation of Carcinogenic Risks to Humans, IARC, Lyon, France, 2012.

Retrieved from:

https://publications.iarc.fr/Book-And-Report-

Series/Iarc-Monographs-On-The-Identification-Of-

Carcinogenic-Hazards-To-Humans/Radiation-2012 Retrieved on: May 27, 2021

5. V. Benkovic, et al., "DNA damage assessment in peripheral blood of Swiss albino mice after combined exposure to volatile anesthetics and 1 or $2 \mathrm{~Gy}$ radiotherapy in vivo," Int. J. Radiat. Biol., vol. 97, no. 10, pp. 1425-1435, Aug. 2021. PMID: 34328801 DOI: 10.1080/09553002.2021.1962565

6. Radiology dose fractionation, $3^{\text {rd }}$ ed., The Royal College of Radiologist, London, UK, 2019.

Retrieved from:

https://www.rcr.ac.uk/publication/radiotherapy-dosefractionation-third-edition Retrieved on: May 1, 2021

7. J. A. Campagna, K. W. Miller, S. A. Forman, "Mechanisms of actions of inhaled anesthetics," N. Engl. J. Med., vol. 348, no. 21, pp. 2110 - 2124, May 2003. DOI: 10.1056/NEJMra021261 PMid: 12761368

8. J. M. Borras et al., "Estimating the number of fractions by tumour site for European countries in 2012 and 2025: An ESTRO-HERO analysis," Radiother. Oncol., vol. 126, no. 2, pp. 198 - 204, Feb. 2018.

DOI: 10.1016/j.radonc.2017.11.009 PMid: 29198408

9. In vivo mammalian alkaline comet assay, OECD guideline for the testing of chemicals TG 489, OECD Paris, France, 2014.

Retrieved from:

https://ntp.niehs.nih.gov/iccvam/suppdocs/feddocs/oe cd/oecd-tg489-2014.pdf

Retrieved on: Apr. 11, 2021

10. M. Neri et al., "Worldwide interest in the comet assay: a bibliometric study," Mutagenesis, vol. 30, no. 1, pp. 155 - 163, Jan. 2015.

DOI: $10.1093 /$ mutage/geuo61 PMid: 25527738

11. M. Milić et al., "The Influence of Individual Genome Sensitivity in DNA Damage Repair Assessment in Chronic Professional Exposure to Low Doses of Ionizing Radiation," in Selected Topics in DNA Repair, C. C. Chen, Eds., Rijeka, Croatia: InTech, 2011, ch. 19, pp. $437-464$ DOI: $10.5772 / 20814$

12. A. Collins, M. Milic, S. Bonassi, M. Dusinska, "The comet assay in human biomonitoring: Technical and epidemiological perspectives," Mutat. Res., vol. 843, pp. 1 - 2, Jul. 2019.

DOI: 10.1016/j.mrgentox.2019.06.002 PMid: 31421730

13. M. Milić et al., "The hCOMET project: International database comparison of results with the comet assay in human biomonitoring. Baseline frequency of DNA damage and effect of main confounders," Mutat. Res. vol. 787, 108371, Jan-Jun. 2021.

DOI: 10.1016/j.mrrev.2021.10837 PMid: 34083035

14. S. Chiao, Z. Zuo, "A double-edged sword: volatile anesthetic effects on the neonatal brain," Brain Sci. vol. 4, no. 2, pp. 273 - 294, Apr. 2014.

DOI: $10.3390 /$ brainsci4020273

PMid: 24961761 PMCid: PMC4101477

15. K. N. Loganovsky, K. L. Yuryev, "EEG patterns in persons exposed to ionizing radiation as a result of the Chernobyl accident. Part 2: quantitative EEG analysis in patients who had acute radiation sickness," J. Neuropsychiatry Clin. Neurosci., vol. 16, no. 1, pp. 70 - 82, Feb. 2004.

DOI: $10.1176 /$ jnp.16.1.70 
PMid: 14990762

16. S. Baluchamy et al., "Reactive oxygen species mediated tissue damage in high energy proton irradiated mouse brain," Mol. Cell Biochem., vol. 360, no. 1 - 2, pp. 189 - 195, Jan. 2012.

DOI: 10.1007/s11010-011-1056-2

PMid: 21948272

17. Croatian Parliament. (Oct. 18, 2017). OG 102/2017. Animal Protection Act.

Retrieved from:

http://www.mvep.hr/files/file/dokumenti/prevodenje/ zakoni/25-Zakon-o-za\%C5\%A1titi-\%C5\%BEivotinja--

NN-102-17-ENG.pdf

Retrieved on: May 21, 2021

18. Hrvatski sabor. (Maj 8, 2013). NN 55/13. Pravilnik o zaštiti životinja koje se koriste u znanstvene surhe.

(Croatian Parliament. (May 8, 2013). OG 55/13. Ordinance on the protection of animals used for scientific purposes.)

Retrieved from:

http://www.veterinarstvo.hr/default.aspx?id=64

Retrieved on: May 21, 2021

19. The European Parliament and the Council of European Union. (Sep. 22, 2010). Directive 2010/63/EU on the protection of animals used for scientific purposes.
Retrieved from:

https://eur-

lex.europa.eu/LexUriServ/LexUriServ.do?uri=OJ:L:201

0:276:0033:0079:en:PDF

Retrieved on: May 21, 2021

20. D. J. Gaertner, T. M. Hallman, F. C. Hankenson, M. A. Batchelder, "Anesthesia and Analgesia for Laboratory Rodents," in Anesthesia and Analgesia in Laboratory Animals, R. E. Fish, M. J. Brown, P. J. Danneman, A.Z. Karas, Eds., 2nd ed., London, UK: Academic Press, 2008, ch. 10, pp. 240 - 261.

Retrieved from:

http://library.lol/main/5Co58EB5162Fo3311F861DE2 A87DDAF4

Retrieved on: May 25, 2021

21. B.A. Siddiqui, P. Y. Kim, Anesthesia Stages, Treasure Island (FL), USA: StatPearls Publishing, 2021. PMid: 32491528

22. G. G. Nair, C. K. Nair, "Protection of cellular DNA and membrane from $\gamma$-radiation-induced damages and enhancement in DNA repair by sesamol," Cancer Biother. Radiopharm., vol. 25, no. 6, pp. 629 - 635, Dec. 2010.

DOI: $10.1089 / \mathrm{cbr} .2010 .0803$

PMid: 21204756 